\title{
KAJIAN PENCEMARAN LINGKUNGAN DI TAMBAK UDANG DELTA MAHAKAM
}

\author{
Salahuddin \\ Mahasiswa Program Doktor Program Studi Ilmu Lingkungan \\ Universitas Gadjah Mada Yogyakarta \\ Email: al.ayuebie@gmail.com \\ Chafid Fandeli \\ Staf Pengajar Program Studi Ilmu Lingkungan \\ Universitas Gadjah Mada Yogyakarta \\ Eko Sugiharto \\ Staf Pengajar Universitas Gadjah Mada Yogyakarta
}

\begin{abstract}
Mahakam Delta has uniqe and productive costal ecosystem and also huge natural resources. If the potentials are well-managed, it will contribute to the improvement of both regional and national economy. However, Mahakam River gets liquid waste pollution that has significant impact on water quality and results in conflicts between the local societies, especially the shrimp pond farmers and the fishermen and the oil and gas industrial company. This research uses descriptive-comparative analysis with ANOVA test to compare samples (water, soil/sediment, shrimp, and mangrove) of the shrimp fishpond (many mangrove, moderate mangrove, few mangrove, and without any mangrove). The pollution load which is analyzed includes: cadmium content $(\mathrm{Cd})$, lead $(\mathrm{Pb})$, oil and grease $(\mathrm{O}$ $\mathcal{E} \mathrm{G})$, mercury $(\mathrm{Hg})$, and arsenic (As). The significance level is $90 \%$ with error of $5 \%(0.05)$.

The water of Mahakam Delta is still in the normality limit as seen from the maximum pollution load in the Decree of the Minister of Living Environment No. 51 of 2004 on Ocean Water Standard seen from chemical, physical, and biological parameters. The presence of mangrove contributes positive value to the balance of the quality of the waters and to the neutralizing of heavy metals contents of Mahakam Delta as shown in the average difference in the $\mathrm{Pb}, \mathrm{Cd}, \mathrm{O} \& \mathrm{G}, \mathrm{As}$ and $\mathrm{Hg}$ of the samples of water, soils/sediment, shrimp and mangrove which are drawn from the of shrimp pond with many mangrove, moderate mangrove, few mangrove and without any mangrove, which is significantly different $(p<0.05)$. Shrimp pond with many mangrove has less average levels of $\mathrm{Pb}, \mathrm{Cd}, \mathrm{M}$ $\mathcal{E} L$, As and Hg compared with the pond with less and without mangrove. The shrimp pond with many mangroves contributes significantly and positively to the prevention of the pollution of $\mathrm{Pb}, \mathrm{Cd}, \mathrm{O}$ and $\mathrm{G}, \mathrm{As}$ and $\mathrm{Hg}$ at low level.
\end{abstract}

Keywords: water pollution, shrimp fishpond and mangrove 
JURNAL TEKKNOSAINS

VOLUME 2

No. 1, 22 Desember 2012

Halaman 1-70

\title{
KAJIAN PENCEMARAN LINGKUNGAN DI TAMBAK UDANG DELTA MAHAKAM
}

\author{
Salahuddin \\ Mahasiswa Program Doktor Program Studi Ilmu Lingkungan \\ Universitas Gadjah Mada Yogyakarta \\ Email: al.ayuebie@gmail.com \\ Chafid Fandeli \\ Staf Pengajar Program Studi Ilmu Lingkungan \\ Universitas Gadjah Mada Yogyakarta \\ Eko Sugiharto \\ Staf Pengajar Universitas Gadjah Mada Yogyakarta
}

\begin{abstract}
ABSTRAK
Delta Mahakam mempunyai ekosistem pesisir yang unik, dan produktif, dan memiliki sumberdaya alam yang sangat besar. Potensi ini apabila dikelola baik, tidak mustahil menjadi kontributor yang mampu meningkatkan perekonomian nasional maupun regional. Perairan Sungai Mahakam mendapat pencemaran limbah cair, sehingga memberikan dampak pada kualitas air, sehingga menjadi penyebab konflik antara masyarakat, khususnya petambak dan nelayan dengan perusahaan industri migas.

Analisis menggunakan diskriptif-komparatif dengan uji ANOVA, untuk membandingkan sampel (air, tanah/sedimen, udang, dan mangrove) dari tambak (banyak mangrove, sedang mangrove, sedikit mangrove, dan tanpa mangrove). Beban pencemaran yang dianalisis: kandungan kadmium (Cd), timbal $(\mathrm{Pb})$, minyak dan lemak $(\mathrm{M} \& \mathrm{~L})$, merkuri $(\mathrm{Hg})$, dan arsenic $(\mathrm{As})$. Tingkat kemaknaan $95 \%$ dengan tingkat kesalahan $5 \%(0,05)$.

Kualitas air tambak udang di Delta Mahakam masih dalam batas kewajaran ditinjau dari beban pencemaran maksimum Keputusan Menteri Negara Lingkungan Hidup No. 51/2004 Tentang Baku Mutu Air Laut dilihat dari parameter kimia, fisika dan biologi. Keberadaan mangrove di tambak udang Delta Mahakam dapat memberikan nilai positif dalam menyeimbangkan kualitas perairan dan menetralisir kadar logam berat, hal ini ditunjukkan dari perbedaan rata-rata kadar $\mathrm{Pb}, \mathrm{Cd}, \mathrm{M} \& \mathrm{~L}$, As, dan Hg dari sampel air, tanah/sedimen, udang dan mangrove yang diambil dari tambak udang bermangrove banyak, bermangrove sedang, bermangrove sedikit, dan tanpa mangrove memperlihatkan berbeda bermakna $(\mathrm{p}<, 05)$. Tambak udang bermangrove banyak lebih sedikit rata-rata kadar $\mathrm{Pb}, \mathrm{Cd}$, $\mathrm{M} \& \mathrm{~L}$, As, dan $\mathrm{Hg}$ dibandingkan tambak undang bermangrove sedang dan bermangrove sedikit. Tambak udang bermangrove banyak memberikan sumbangan positif dalam pencegahan pencemaran yang berupa kadar $\mathrm{Pb}, \mathrm{Cd}, \mathrm{M}$ dan $\mathrm{L}$, As, dan $\mathrm{Hg}$ yang rendah.
\end{abstract}

Kata Kunci: pencemaran air, tambak udang, mangrove 


\section{PENGANTAR}

Delta Mahakam adalah suatu kawasan berbentuk kipas, dengan pinggiran luarnya berbentuk hampir setengah lingkaran (fanshaped lobate), yang terbentuk dari proses sedimentasi sejak 5000 tahun yang lalu pada muara Sungai Mahakam di kawasan pantai timur Provinsi Kalimantan Timur. Kawasan Delta ini berupa kawasan dataran berlumpur ("delta plain") yang hampir keseluruhannya berupa rawa-rawa dengan alur-alur sungai dan anak-anak sungai yang memotong bagian daratannya, kawasan pasang surut berpasir/ paparan delta (delta front), dan kawasan yang tersusun dari batu lempung menunjam ke arah laut terbuka dan selalu tergenang air laut/prodelta.

Delta Mahakam secara alami ditutupi oleh nipah (Nypah fruticans) sebagai vegetasi dominan, diikuti oleh beberapa jenis tumbuhan mangrove, seperti Api-api (Avicennia spp), dan bakau (Rhizophora spp), luas tutupan nipah (Nypah fruticans) terbesar di dunia. Ekosistem Delta Mahakam memiliki produktivitas hayati yang sangat tinggi dan mendapat pasokan bahan organik potensial sebagai hara dari lahan atas melalui aliran sungai. Oleh karena itu, ekosistem ini memiliki potensi sumberdaya alam hayati (renewable resources) seperti: ikan, udang, dan kepiting yang sangat besar. Selain potensi sumberdaya alam hayati, ekosistem Delta Mahakam juga memiliki sumberdaya alam nir-hayati seperti minyak dan gas bumi potensial. Kedua jenis sumberdaya alam potensial tersebut di atas, menjadikan ekosistem Delta Mahakam memiliki nilai yang amat penting bagi pembangunan berbasis sumberdaya alam hayati (perikanan) dan nir-hayati (minyak dan gas bumi) di Provinsi Kalimantan Timur umumnya dan Kabupaten Kutai Kartanegara khususnya.

Udang windu hidup pada paramaeter kualitas air yang lebar dan toleran terhadap kandungan oksigen terlarut sangat rendah. Udang windu dipelihara pada lingkungan dengan substrat berbatu dan berlumpur memiliki pertumbuhan yang lebih cepat dibanding dengan yang dipelihara pada substrat buatan. Pertumbuhan yang optimal, untuk udang windu adalah dipelihara pada suhu $25-29^{\circ} \mathrm{C}$, hidup pada kisaran $\mathrm{pH}$ 7-9, dan udang windu sensitif terhadap kadar klorin yang tinggi. Salinitas dalam budidaya udang windu ini sebaiknya tidak melebihi 5\% Semakin asin air maka tingkat pertumbuhan semakin melambat, hal ini ditandai dengan semakin jarangnya udang windu tersebut mengganti kulit dan tingkat mortalitas semakin tinggi. Udang windu tumbuh optimal bila salinitas air menunjukan 5\%.

Lingkungan Delta Mahakam juga memiliki potensi cadangan minyak dan gas bumi yang sangat besar. Eksploitasi Delta Mahakam untuk kegiatan eksplorasi dan eksploitasi migas dilakukan oleh beberapa perusahaan kontraktor swasta asing, seperti: perusahaan Total Eksploitasi dan Produksi (E\&P) yang beroperasi di bagian offshore dan Vico di bagian onshore delta. Perusahaan Total (E\&P) Indonesie Balikpapan telah mengikat kontrak karya tahun 1966 dengan Pemerintah Indonesia, mulai dilakukan eksplorasi tahun 1971, dan berproduksi tahun 1974. Demikian juga dengan bagian onshore di Muara Badak telah dimulai tahun 1968 dengan kontrak kerja selama 30 tahun. Pada tahun 1971 eksplorasi dimulai oleh perusahaan Huffco Indonesia dan kemudian dilanjutkan dengan eksploitasi produksinya oleh perusahaan Vico.

Kegiatan pembangunan khususnya minyak, gas, dan panas bumi pada umumnya mempunyai potensi yang menimbulkan dampak yang bersifat positif maupun negatif terhadap lingkungan alam (ekosistem) maupun lingkungan masyarakat (ekonomi, sosial, budaya, dan politik). Kegiatan industri migas memiliki potensi yang cukup tinggi untuk terjadinya pencemaran lingkungan. Limbah yang dihasilkan dari setiap kegiatan industri mempunyai kecenderungan untuk menimbulkan dampak negatif terhadap kondisi lingkungan sekitarnya, apabila limbah industri yang dibuang ke lingkungan tidak dikelola secara sempurna sehingga melampaui 
baku mutu yang telah ditetapkan. Perubahanperubahan kondisi kualitas/lingkungan perairan yang melebihi ambang batas toleransi mengakibatkan timbulnya berbagai permasalahan pada proses pembudidayaan. Ekses dari kegiatan ini tentunya juga dapat merusak ekosistem hutan mangrove dan meningkatkan potensi pencemaran laut akibat tumpahan minyak. Meskipun telah ada standar keamanan lingkungan, tetapi ancaman pencemaran laut tidak langsung hilang.

Daerah Delta Mahakam Kabupaten Kutai Kartanegara Kalimantan Timur merupakan salah satu daerah produksi dan eksplorasi minyak oleh industri migas. Sektor pertambangan ini berada pada aliran Sungai Mahakam, sehingga daerah ini tidak dapat melepaskan diri dari efek negatif yang ditimbulkan.Kegiatan produksidaneksplorasi minyak dapat mempengaruhi kualitas air yang berada di daerah tersebut. Bahan-bahan sisa industri dan kegiatan pertambangan baik yang bersifat padat maupun cair berpengaruh terhadap lingkungan sekitarnya. Bahan sisa induksi yang dilepaskan ke perairan bebas akan mempengaruhi perairan dengan terjadinya perubahan nilai perairan baik kualitas maupun kuantitas sehingga perairan dapat dianggap tercemar. Untuk itu, agar air buangan tadi tidak mencemari sungai, laut dan lingkungan hidup, pemerintah dalam hal ini Menteri Negara Kependudukan dan Lingkungan Hidup menetapkan Baku Mutu Air Limbah yang tertuang dalam Kep 51/ Men KLH/II/2004. Ada delapan parameter penting bahwa jumlah kandungan dalam air buangan tidak boleh dilampaui besarnya. Parameter-parameter tersebut adalah Krora hexavalen, Amonia bebas, Sulfida, Phenol, Minyak mineral, BOD, COD, dan $\mathrm{pH}$.

Di kawasan Delta Mahakam sering terjadi konflikantaramasyarakat,khususnya petambak dan nelayan dengan perusahaan industri migas. Konflik terjadi karena ada dugaan bahwa pencemaran lingkungan disebabkan air limbah yang dihasilkan oleh kegiatan industri migas. Air limbah dari kegiatan industri termasuk perusahaan minyak dan gas yaitu air terproduksi yang berasal dari sumur-sumur produksi yang dialirkan ke instalasi pengolahan air limbah (IPAL) yang kemudian dibuang ke laut. Lingkungan Delta Mahakam terletak di pesisir Delta Mahakam. Air yang digunakan untuk memelihara udang lingkungan Delta Mahakam adalah air laut yang berasal dari air yang ada di pesisir delta. Perusahaan mengklaim bahwa aktivitas eksplorasi maupun eksploitasi mereka telah dikontrol secara ketat dan telah melalui prosedur yang baku. Masyarakat petambak berpendapat perusahaan telah mencemari lingkungan sehingga menurunkan produktivitas tambaknya.

Prioritas pembangunan yang berkaitan langsung dengan pengendalian pencemaran lingkungan adalah optimalisasi distribusi dan kualitas sumberdaya alam Sungai Mahakam serta rehabilitasi kawasan konservasi dan kelestarian lingkungan hidup. Untuk itu, RencanaStrategis Daerah Provinsi Kalimantan Timur menargetkan pada tahun 2010 bahwa Kualitas air sungai COD (mg/ltr) standar = 10 minimal 26,00 dan BOD (mg/ltr) standar= 6 minimal 12,00. Air yang diperuntukkan bagi keperluan domestik sebaiknya bebas dari kandungan minyak (oil) dan grease (lemak) karena air dengan kadar petrolium relatif tinggi menimbulkan rasa dan bau yang tidak enak. Kandungan minyak di perairan untuk keperluan air minum sebaiknya tidak melebihi $0,2 \mathrm{mg} /$ liter.

Mengingat perairan Sungai Mahakam di daerah Delta Mahakam yang potensial mendapat pencemaran limbah terutama limbah cair yang dapat memberikan dampak pada kualitas air lingkungan, maka perlu untuk mengadakan penelitian tentang kajian dampak limbah cair di lingkungan Delta Mahakam Kabupaten Kutai Kartanegara Kalimantan Timur.

\section{Alat dan Bahan}

Delta Mahakam merupakan delta muara Sungai Mahakam yang masuk kawasan Kabupaten Kutai Kartanegara, Kalimantan 
Timur. Waktu pelaksanaan penelitian di mulai dari kegiatan survei lapangan pada bulan September 2011. Pengambilan sampel air, udang, tanah/sedimen dan mangrove mulai bulan Januari sampai dengan Maret 2012.

Metode survei ini menekankan pada survei data primer yang didukung dengan berbagai data sekunder. Cara memperoleh data primer dilakukan dengan menggunakan teknik sampling. Sampel pengamatan diambil berupa sampel udang, sedimen/tanah, air, dan mangrove dalam tambak.

Bahan atau materi Pengamatan yang digunakan adalah limbah cair buangan dari industri migas di Delta Mahakam dan sampel air sungai dan air tambak udang di Delta Mahakam, yaitu pada hulu delta sebelum dialiri limbah cair dan sesudah dialiri limbah cair. Selanjutnya bahan dasar ini ditelaah dan di analisis mengenai sifat fisika, komposisi kimia, dan biologisnya.

Peralatan terbagi menjadi dua bagian yaitu Pertama, Pencatatan untuk pengukuran di lapangan seperti: temperatur, $\mathrm{pH}$, pengambilan sampel air limbah, dan air sungai serta pengukuran debit. Kedua, Peralatan laboratorium yang diperlukan untuk pengukuran $\mathrm{pH}$, temperatur, BOD, COD, Amonia bebas, Sulfida, Phenol, dan Minyak mineral. Tahapan yang dilakukan dalam pengamatan ini sebagai berikut:

1. Tahap pendahuluan mencakup kegiatan menyiapkan peta lokasi penelitian, kompilasi data yang tediri dari data primer, dan data sekunder. Data sekunder terdiri dari data morfologi, data hidrologi, dan data industri migas. Data primer terdiri dari data kondisi sungai dan tambak udang, data hidrogeologi, data organisme air sungai dan air tambak udang, data hidro energi, dan data kualitas air sungai dan air tambak udang. Hasil dari kompilasi data kemudian dijadikan data untuk penentuan simulasi penyebaran limbah cair industri migas. Sebelum dilakukan simulasi terlebih dahulu dilakukan validasi data dan penentuan parameter simulasi. Hasil dari simulasi dapat diketahui model penyebaran limbah cair industri migas.

2. Survey lapangan untuk penentuan lokasi dan titik pengambilan sampel.

3. Evaluasi kualitas lingkungan perairan untuk menentukan parameter sampel.

4. Tahap pelaksanaan di lapangan adalah kegiatan pengambilan sampel pada lokasi dan titik yang telah ditentukan dan pengukuran parameter-parameter yang dapat berubah dengan cepat dan tidak dapat diawetkan seperti; suhu, $\mathrm{pH}$, salinitas, dan oksigen terlarut. Sampel lain yang diambil adalah air, tanah/ sedimen, udang dan mangrove dari tambak undang yang bermangrove banyak, sedang, sedikit, dan tanpa mangrove. Pengambilan sampel ini untuk melihat kadar kadmium (Cd), timbal $(\mathrm{Pb})$, minyak dan lemak $(\mathrm{M} \&$ $\mathrm{L})$, merkuri (Hg), dan arsenic (As).

5. Tahap analisis sampel adalah tahap melakukananalisis sampelyang dilakukan di laboratorium Pusrehut Universitas Mulawarman Kalimantan Timur.

6. Tahap pengolahan data dan penyusunan laporan. Pengolahan data adalah kegiatan pengelompokan dari parameter-parameter yang telah diukur langsung di lapangan dari setiap sampel maupun yang dianalisis di laboratorium. Hasilnya berupa data, yang diklasifikasikan dalam bentuk tabel dan grafik.

7. Penyusunan laporan dilakukan untuk menyajikan informasi hasil penelitian.

Analisis data menggunakan analisis komparatif uji ANOVA. Analisis dilakukan dengan membandingkan sampel (air, tanah/ sedimen, udang, dan mangrove) yang diambil dari tambak (banyak mangrove, sedang mangrove, sedikit mangrove, dan tanpa mangrove). Beban 
pencemaran yang dianalisis adalah kandungan kadmium $(\mathrm{Cd})$, timbal $(\mathrm{Pb})$, minyak dan lemak (M\& L), merkuri (Hg), dan arsenic (As). Tingkat kemaknaan uji statistik adalah $95 \%$ dengan tingkat kesalahan $5 \%(0,05)$.

\section{PEMBAHASAN}

Hasil laboratorium sampel air sungai di Delta Mahakam, untuk mengetahui beban pencemaran industri migas yang dibandingkan dengan beban pencemaran maksimum menurut Keputusan Menteri, terlihat pada tabel 1 .

Tabel 1. Beban pencemaran industri migas sekitar Delta Mahakam

\begin{tabular}{|l|l|l|l|l|}
\hline No. & \multicolumn{1}{|c|}{ Parameter } & Satuan & \multicolumn{1}{|c|}{ Beban Pencemaran } & $\begin{array}{l}\text { Beban Pencemaran maksimum menurut Kep } \\
\text { 42/Men KLH/II/2004 }\end{array}$ \\
\hline 1 & BOD & $\mathrm{mg} / \mathrm{l}$ & 28,7 & 80 \\
\hline 2 & COD & $\mathrm{mg} / \mathrm{l}$ & 33,1 & 160 \\
\hline 3 & Minyak Lemak & $\mathrm{mg} / 1$ & - & 20 \\
\hline 4 & Sulfida Terlarut (H2S) & $\mathrm{mg} / \mathrm{l}$ & - & 0.5 \\
\hline 5 & Amonia Terlarut (NH3-N) & $\mathrm{mg} / 1$ & 19 & 0.5 \\
\hline 6 & Phenol Total & $\mathrm{mg} / \mathrm{l}$ & 0.109 & 0.5 \\
\hline
\end{tabular}

Hasil analisis kualitas air lingkungan Delta Mahakam baik secara fisik, kimia, dan biologis disajikan pada tabel 2 dan tabel 3 berikut:

Tabel 2. Tingkat Pencemaran Lingkungan Delta Mahakam

\begin{tabular}{|c|c|c|c|c|c|c|c|c|c|c|}
\hline \multirow{2}{*}{ No. } & \multirow{2}{*}{ Parameter } & \multirow{2}{*}{ Satuan } & \multicolumn{6}{|c|}{ Hasil Uji } & \multirow{2}{*}{ Metode Uji } & \multirow{2}{*}{ Batas Syarat } \\
\hline & & & S1 & S1 & S2 & S2 & S3 & S3 & & \\
\hline 1 & Suhu & ${ }^{\circ} \mathrm{C}$ & 28 & 28 & 28 & 28 & 28 & 28 & $\begin{array}{l}\text { IK/ } \\
\text { BBTKLPPM/3-K/ } \\
\text { Pjc-01 }\end{array}$ & 45 \\
\hline 2 & $\mathrm{pH}$ & - & 7.8 & 7.9 & 7.9 & 7.9 & 8.0 & 7.5 & $\begin{array}{l}\text { IK/ } \\
\text { BBTKLPPM/3-K/ } \\
\text { Pjc-02 }\end{array}$ & $6,0-9,0$ \\
\hline 3 & BOD & $\mathrm{mg} / \mathrm{l}$ & 3.3 & 2.9 & 4.7 & 3.1 & 9.6 & 2.3 & $\begin{array}{l}\text { APHA, 2006, Section } \\
5210\end{array}$ & 80 \\
\hline 4 & COD & $\mathrm{mg} / \mathrm{l}$ & 16 & 16 & 24 & 24 & 32 & 16 & $\begin{array}{l}\text { APHA, 2006, Section } \\
5220\end{array}$ & 160 \\
\hline 5 & $\begin{array}{l}\text { Sulfida } \\
\text { Terlarut } \\
(\mathrm{H} 2 \mathrm{~S}) \\
\end{array}$ & $\mathrm{mg} / \mathrm{l}$ & $\begin{array}{l}\text { tak } \\
\text { ter- } \\
\text { deteksi }\end{array}$ & $\begin{array}{l}\text { tak ter- } \\
\text { deteksi }\end{array}$ & $\begin{array}{l}\text { tak } \\
\text { ter- } \\
\text { deteksi }\end{array}$ & $\begin{array}{l}\text { tak ter- } \\
\text { deteksi }\end{array}$ & $\begin{array}{l}\text { tak ter- } \\
\text { deteksi }\end{array}$ & $\begin{array}{l}\text { tak ter- } \\
\text { deteksi }\end{array}$ & SNI 19-1664-1997 & 0.5 \\
\hline 6 & $\begin{array}{l}\text { Amonia } \\
\text { Terlarut } \\
(\mathrm{NH} 3-\mathrm{N})\end{array}$ & $\mathrm{mg} / \mathrm{l}$ & 0.0202 & 0.0205 & 0.0236 & 0.0193 & 0.0346 & 0.0106 & SNI 06-2749-1999 & 5 \\
\hline 7 & $\begin{array}{l}\text { Phenol } \\
\text { Total }\end{array}$ & $\mathrm{mg} / \mathrm{l}$ & $\begin{array}{l}\text { tak } \\
\text { ter- } \\
\text { deteksi }\end{array}$ & 0.0559 & 0.0074 & 0.0372 & $\begin{array}{l}\text { tak } \\
\text { ter- } \\
\text { deteksi }\end{array}$ & 0.0379 & SNI 06-2469-1999 & 0.5 \\
\hline
\end{tabular}

Keterangan: S1: sampel air diambil dari aliran sungai sebelum tertumpah limbah minyak, S2: sampel air diambil dari aliran sungai sesudah tertumpah limbah minyak; dan S3: sampel air diambil dari tambak udang tanpa mangrove

Hasil penelitian pada tabel 2 sampel diambil dari aliran sungai sebelum tertumpah limbah minyak, aliran sungai sesudah tertumpah limbah minyak, dan air diambil dari tambak udang tanpa mangrove. Untuk tabel 3, dilihat tingkat pencemaran di dalam tambak udang di Delta Mahakam di mana pengambilan sampel dipilih untuk tambak udang yang semimangrove dan tambak udang full-magrove.

Beban pencemaran yang ada di lingkungan Delta Mahakam dilihat dari logam berat yang terkandung dalam sampel penelitian yang terdiri dari air, tanah/ sedimen, udang, dan mangrove. Sampel 
diambil dari tambak udang dari beberapa kelompok tambak yaitu banyak mangrove, sedang mangrove, sedikit mangrove, dan tanpa mangrove. Sampel penelitian dilihat kandungan logam berat yang terdiri dari kandungan timbal $(\mathrm{Pb})$, kadmium $(\mathrm{Cd})$, minyak dan lemak (M \& L), merkuri $(\mathrm{Hg})$, dan Arsenim (As).

Hasil penelitian untuk melihat perbedaan rata-rata kandungan Timbal $(\mathrm{Pb})$ dengan masing-masing kelompok tambak dapat dilihat pada tabel 3 dan gambar 1.

Tabel 3.

Rata-rata kandungan Timbal/Pb (mg/kg) pada sampel udang, sedimen/tanah, air dan mangrove pada kelompok tambak tanpa mangrove, sedikit mangrove, sedang mangrove dan banyak mangrove

\begin{tabular}{|l|l|l|l|l|l|}
\hline \multirow{2}{*}{ No. } & \multirow{2}{*}{ Kelompok Tambak } & \multicolumn{4}{|c|}{ Rata-rata kandungan Timbal/Pb (mg/kg) } \\
\cline { 3 - 6 } & & \multicolumn{1}{|c|}{ Udang } & \multicolumn{1}{|c|}{ Tanah } & Air & Mangrove \\
\hline 1. & Tanpa mangrove & $1,905 \pm 0,067$ & $903,46 \pm 773,95$ & $0,205 \pm 0,022$ & - \\
\hline 2. & Sedikit mangrove & $1,765 \pm 0,064$ & $319,72 \pm 67,58$ & $0,153 \pm 0,011$ & $123,04 \pm 75,86$ \\
\hline 3. & Sedang mangrove & $1,602 \pm 0,044$ & $133,57 \pm 40,12$ & $0,120 \pm 0,018$ & $306,83 \pm 89,03$ \\
\hline 4. & Banyak mangrove & $1,238 \pm 0,120$ & $75,27 \pm 17,09$ & $0,085 \pm 0,033$ & $703,55 \pm 395,68$ \\
\hline$p$ & $0,002^{*}$ & $0,027^{*}$ & 0,139 & 0,147 \\
\hline
\end{tabular}

${ }^{*} \mathrm{p}<0,05$ secara statistik bermakna/signifikan
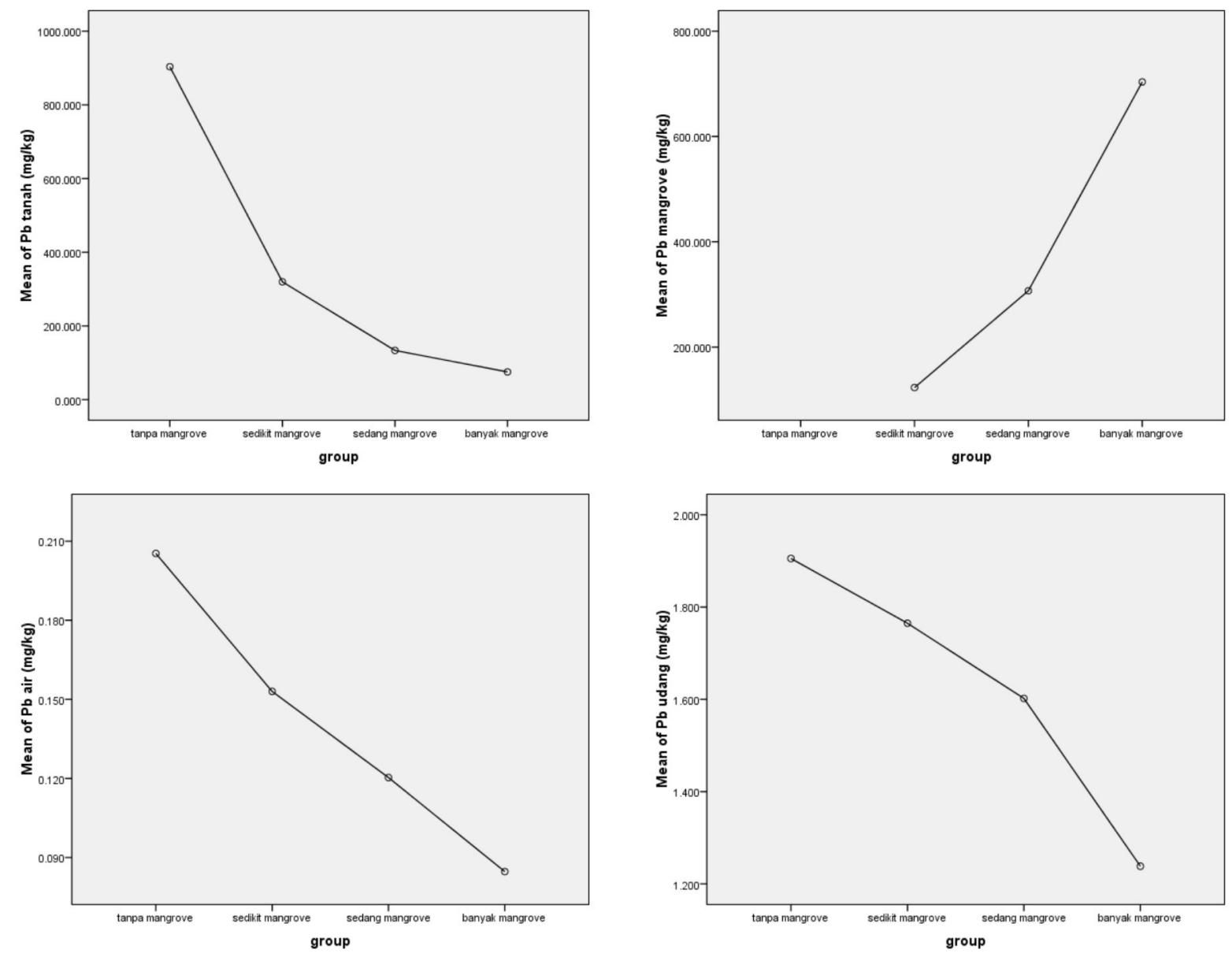

Gambar 1.

Perbedaan rata-rata kandungan timbal/ $\mathrm{Pb}(\mathrm{mg} / \mathrm{kg})$ pada sampel udang, sedimen/tanah, air dan mangrove pada kelompok tambak tanpa mangrove, sedikit mangrove, sedang mangrove, dan banyak mangrove 
Hasil penelitian untuk melihat perbedaan rata-rata kandungan Cadmium (Cd) dengan masing-masing kelompok tambak dapat dilihat pada tabel 4 dan gambar 2 .

Tabel 4.

Rata-rata kandungan Cadmium/Cd (mg/ kg) pada sampel udang, sedimen/tanah, air, dan mangrove pada kelompok tambak tanpa mangrove, sedikit mangrove, sedang mangrove, dan banyak mangrove

\begin{tabular}{|l|l|l|l|l|l|}
\hline \multirow{2}{*}{ No. } & \multirow{2}{*}{ Kelompok } & \multicolumn{4}{|c|}{ Rata-rata kandungan Cadmium/Cd $(\mathrm{mg} / \mathrm{kg})$} \\
\cline { 3 - 6 } & & Udang & \multicolumn{1}{c|}{ Tanah } & Air & \multicolumn{1}{c|}{ Mangrove } \\
\hline 1. & Tanpa mangrove & $0,167 \pm 0,005$ & $1,82 \pm 0,184$ & $0,024 \pm 0,0010$ & - \\
\hline 2. & Sedikit mangrove & $0,154 \pm 0,003$ & $1,25 \pm 0,312$ & $0,021 \pm 0,0012$ & $0,40 \pm 0,097$ \\
\hline 3. & Sedang mangrove & $0,146 \pm 0,004$ & $0,85 \pm 0,040$ & $0,016 \pm 0,0010$ & $0,70 \pm 0,105$ \\
\hline 4. & Banyak mangrove & $0,129 \pm 0,007$ & $0,66 \pm 0,104$ & $0,013 \pm 0,0010$ & $1,28 \pm 0,298$ \\
\hline$p$ & & $0,030^{*}$ & 0,097 & 0,940 & 0,533 \\
\hline
\end{tabular}

* $\mathrm{p}<0,05$ secara statistik bermakna/signifikan
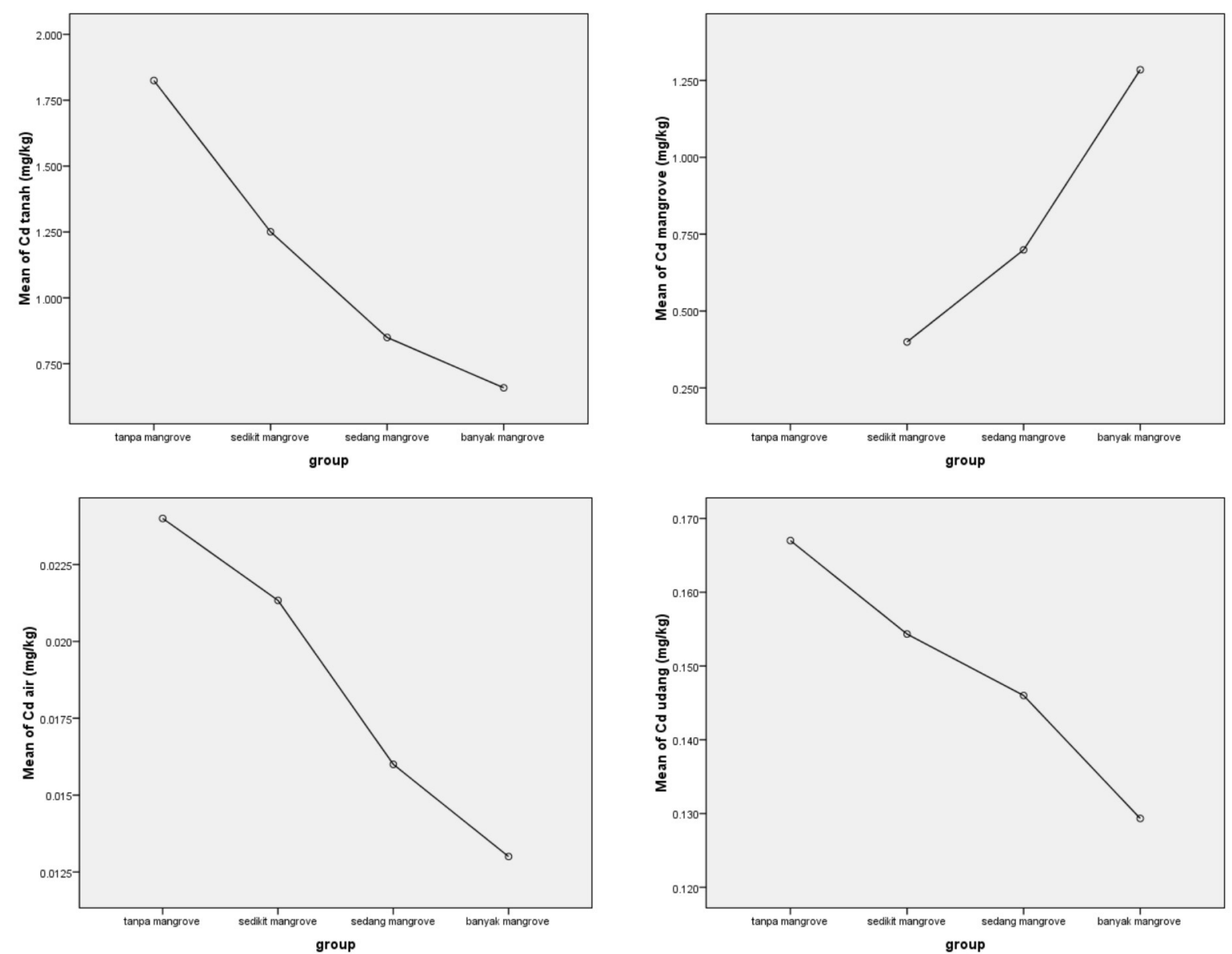

Gambar 2.

Perbedaan rata-rata kandungan Cadmium/Cd $(\mathrm{mg} / \mathrm{kg})$ pada sampel udang, sedimen/tanah, air dan mangrove pada kelompok tambak tanpa mangrove, sedikit mangrove, sedang mangrove dan banyak 
Hasil untuk melihat perbedaan rata-rata kandungan minyak dan lemak ( $\mathrm{M} \& \mathrm{~L}$ ) dengan masing-masing kelompok tambak dapat dilihat pada tabel 5 dan gambar 3.

Tabel 5.

Rata-rata kandungan minyak dan lemak (M \& L) pada sampel udang, sedimen/tanah, air, dan mangrove pada kelompok tambak tanpa mangrove, sedikit mangrove, sedang mangrove dan banyak mangrove

\begin{tabular}{|l|l|l|l|l|l|}
\hline \multirow{2}{*}{ No. } & \multirow{2}{*}{ Kelompok } & \multicolumn{3}{|c|}{ Rata-rata kandungan Minyak dan Lemak (M \& $)$} \\
\cline { 3 - 6 } & & \multicolumn{1}{|c|}{ Udang } & \multicolumn{1}{c|}{ Tanah } & \multicolumn{1}{c|}{ Air } & \multicolumn{1}{c|}{ Mangrove } \\
\hline 1. & Tanpa mangrove & $6,89 \pm 0,659$ & $5,36 \pm 0,951$ & $32,11 \pm 22,384$ & - \\
\hline 2. & Sedikit mangrove & $5,06 \pm 0,030$ & $5,56 \pm 0,536$ & $10,33 \pm 2,350$ & $13,32 \pm 0,308$ \\
\hline 3. & Sedang mangrove & $4,51 \pm 0,340$ & $5,88 \pm 0,579$ & $5,58 \pm 1,600$ & $14,38 \pm 0,452$ \\
\hline 4. & Banyak mangrove & $3,37 \pm 0,581$ & $5,39 \pm 0,586$ & $3,23 \pm 0,129$ & $15,86 \pm 0,655$ \\
\hline$p$ & 0,302 & 0,603 & $0,002^{*}$ & 0,171 \\
\hline
\end{tabular}

* $\mathrm{p}<0,05$ secara statistik bermakna/signifikan
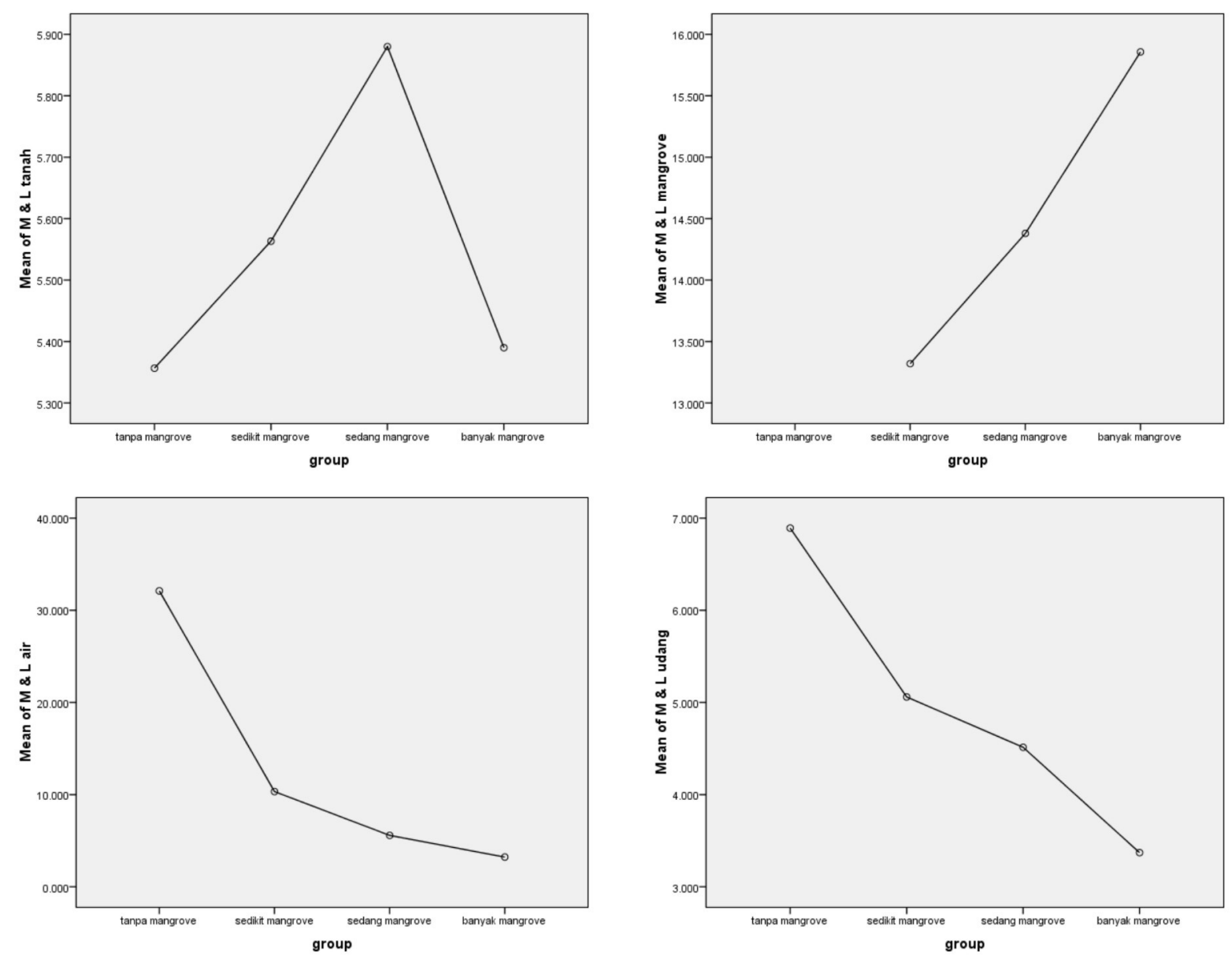

Gambar 3.

Perbedaan rata-rata kandungan minyak dan lemak (M \& L) pada sampel udang, sedimen/tanah, air dan mangrove pada kelompok tambak tanpa mangrove, sedikit mangrove, sedang mangrove, dan banyak mangrove. 
Hasil pengamatan untuk melihat perbedaan rata-rata kandungan Arsenik (As) dengan masing-masing kelompok tambak dapat dilihat pada tabel 6.

Tabel 6.

Rata-rata kandungan Arsenik/As (mg/kg) pada sampel udang, sedimen/tanah, air dan mangrove pada kelompok tambak tanpa mangrove, sedikit mangrove, sedang mangrove, dan banyak mangrove

\begin{tabular}{|l|l|l|l|l|l|}
\hline \multirow{2}{*}{ No. } & \multirow{2}{*}{ Kelompok } & \multicolumn{4}{|c|}{ Rata-rata kandungan Arsenik/As (mg/kg) } \\
\cline { 3 - 6 } & & Udang & Tanah & Air & \multicolumn{1}{|c|}{ Mangrove } \\
\hline 1. & Tanpa mangrove & $0,001 \pm 0,000$ & $0,001 \pm 0,000$ & $0,001 \pm 0,000$ & - \\
\hline 2. & Sedikit mangrove & $0,001 \pm 0,000$ & $0,001 \pm 0,000$ & $0,001 \pm 0,000$ & $0,001 \pm 0,000$ \\
\hline 3. & Sedang mangrove & $0,001 \pm 0,000$ & $0,001 \pm 0,000$ & $0,001 \pm 0,000$ & $0,001 \pm 0,000$ \\
\hline 4. & Banyak mangrove & $0,001 \pm 0,000$ & $0,001 \pm 0,000$ & $0,001 \pm 0,000$ & $0,001 \pm 0,000$ \\
\hline $\mathrm{p}$ & - & - & - & - \\
\hline
\end{tabular}

${ }^{*} \mathrm{p}<0,05$ secara statistik bermakna/signifikan

Hasil pengamatan untuk melihat perbedaan rata-rata kandungan Merkuri (Hg) dengan masing-masing kelompok tambak dapat dilihat pada tabel 7.

Tabel 7.

Rata-rata kandungan Merkuri/Hg (mg/kg) pada sampel udang, sedimen/tanah, air dan mangrove pada kelompok tambak tanpa mangrove, sedikit mangrove, sedang mangrove dan banyak mangrove

\begin{tabular}{|l|l|l|l|l|l|}
\hline \multirow{2}{*}{ No. } & \multirow{2}{*}{ Kelompok } & \multicolumn{4}{|c|}{ Rata-rata kandungan Merkuri/Hg (mg/kg) } \\
\cline { 3 - 6 } & & Udang & Tanah & Air & Mangrove \\
\hline 1. & Tanpa mangrove & $0,0005 \pm 0,000$ & $0,0005 \pm 0,000$ & $0,0005 \pm 0,000$ & - \\
\hline 2. & Sedikit mangrove & $0,0005 \pm 0,000$ & $0,0005 \pm 0,000$ & $0,0005 \pm 0,000$ & $0,0005 \pm 0,000$ \\
\hline 3. & Sedang mangrove & $0,0005 \pm 0,000$ & $0,0005 \pm 0,000$ & $0,0005 \pm 0,000$ & $0,0005 \pm 0,000$ \\
\hline 4. & Banyak mangrove & $0,0005 \pm 0,000$ & $0,0005 \pm 0,000$ & $0,0005 \pm 0,000$ & $0,0005 \pm 0,000$ \\
\hline P & - & - & - & - \\
\hline
\end{tabular}

${ }^{*} \mathrm{p}<0,05$ secara statistik bermakna/signifikan

\section{PEMBAHASAN}

Upaya pemantauan kualitas air perlu dilakukan untuk mengetahui suatu perairan masih dalam kondisi aman atau telah tercemar. Salah satu upaya yang dapat dilakukan adalah dengan melakukan simulasi sebaran kualitas air laut akibat buangan air terproduksi dengan prediksi hidrodinamika dan kualitas air laut secara cepat dan akurat. Pada tabel 1 terlihat bahwa beban pencemaran industri migas di sekitar Delta Mahakam masih dalam batas kewajaran ditinjau dari beban pencemaran maksimum menurut Keputusan Menteri Negara Lingkungan Hidup Nomor 51 Tahun 2004 Tentang Baku Mutu Air Laut.

Tingkat pencemaran lingkungan Delta Mahakam diperlihatkan pada tabel 2. Hasil penelitian terlihat bahwa sampel air yang diambil dari sungai sebelum tertumpah limbah, sampel air yang diambil dari sungai sesudah tertumpah limbah minyak, dan sampel air yang diambil dari tambak udang tanpa mangrove berdasarkan suhu, $\mathrm{pH}, \mathrm{BOD}$, $\mathrm{COD}, \mathrm{H}_{2} \mathrm{~S}, \mathrm{NH} 3-\mathrm{N}$, dan Phenol total masih di bawah batas syarat Keputusan Menteri Negara Lingkungan Hidup Nomor 51 Tahun 2004 Tentang Baku Mutu Air Laut. Akan tetapi, pH, BOD, COD, NH3-N, dan Phenol Total menunjukkan peningkatan pada pengukuran sampel air yang diambil dari sungai sesudah tertumpah limbah minyak dan sampel air yang diambil dari tambak udang tanpa mangrove. Berdasarkan data ini, perlu kewaspadaan terhadap pencemaran limbah yang ditimbulkan dari industri, sehingga kualitas air dapat tetap dipertahankan untuk kepentingan umum. Indikator yang digunakan untuk menentukan kualitas air adalah BOD, COD, $\mathrm{pH}$, suhu, $\mathrm{NH}_{3}, \mathrm{NH} 3-\mathrm{N}$, dan Phenol total karena bahan 
mewakili parameter fisik, parameter kimia, dan parameter biologis.

Biological Oxigen Demand (BOD) dipakai sebagai salah satu indikator khemis yang mencerminkan aktivitas kehidupan di dalam air dan dapat digunakan sebagai indikator kuantitas bahan organik yang terlarut. Pemeriksaan BOD adalah pengukuran yang sudah dibakukan untuk jumlah oksigen yang dibutuhkan oleh mikrorganisme untuk memecah bahan-bahan organik di dalam air. Secara sederhana pengertian pengukuran BOD dari beban pencemaran organik diukur dengan banyaknya kebutuhan oksigen yang ada dalam suatu aliran untuk oksidasi. Makin tinggi BOD makin tinggi tingkat pencemaran. Tes BOD merupakan tes yang paling informatif dalam pengoperasian dan pengendalian instalasi pengolah limbah karena angka BOD dapat digunakan untuk mengetahui jumlah air pengencer yang dibutuhkan untuk pembuangan limbah secara efisien. Tes BOD secara luas juga digunakan untuk menentukan daya pencemaran atau kekuatan air limbah domestik dan industri dalam arti kata oksigen yang akan mereka butuhkan apabila dibuang kedalam suatu badan air. Oleh karena itu, BOD penting dalam aktivitas pengendalian pencemaran. Dalam penelitian ini didapat harga BOD 3,1 mg/1 dan 24,6 $\mathrm{mg} / 1$, masing-masing untuk pengukuran air sungai di Delta Mahakam sebelum dan setelah melewati tempat pembuangan limbah cair industri migas sekitar Delta Mahakam. Nilai BOD air sungai di Delta Mahakam hasil observasi sebelum melewati industri adalah 3,1 mg/l (Co), debit aliran sungai di Delta Mahakam 442,68 m3/dt (Qo), debit limbah cair buangan 0,0021 l/detik (Q1), dan nilai BOD limbah cair 24,6 mg/l (C1). Perhitungan nilai BOD air sungai di Delta Mahakam setelah melalui lokasi pembuangan limbah cair industri migas sekitar Delta Mahakam $3,47 \mathrm{mg} / 1$. Ternyata limbah cair buangan dari industri migas sekitar Delta Mahakam hanya menaikkan kecil sekali nilai BOD air sungai di Delta Mahakam, artinya jumlah oksigen yang dibutuhkan oleh bakteri untuk menguraikan (mengoksidasikan) semua zat organis yang tersuspensi dalam limbah cair buangan ini cukup kecil. Dari hasil analisis laboratorium nilai BOD 11,1mg/1. Dari nilai BOD ini dapat diterangkan bahwa jumlah oksigen yang dibutuhkan oleh bakteri untuk menguraikan (mengoksidasikan) semua zat organis yang tersuspensi dalam air sungai di Delta Mahakam tidak hanya berasal dari limbah cair buangan industri migas sekitar Delta Mahakam saja. Dari hasil analisis laboratorium nilai BOD 3,47 mg/1. Dapat diterangkan di sini bahwa debit air sungai di Delta Mahakam yang sangat besar merupakan air pengencer yang menyebabkan nilai $\mathrm{BOD}$ menurun.

Chemical Oxigen Demand (COD) adalah pengukuran konsentrasi substansisubstansi yang ada di dalam air yang bisa bereaksi dengan bahan pengoksidasi yang kuat (biasanya dipakai bahan oksidator dari Dikhromat). COD adalah jumlah atau banyaknya oksigen yang dipakai untuk mengoksidasi zat karbon organik yang ada di perairan, kecuali senyawa aromatis tertentu seperti benzena. Angka COD merupakan ukuran bagi pencemaran air oleh zat-zat organis yang secara alamiah dapat dioksidasikan melalui proses mikrobiologis dan mengakibatkan berkurangnya oksigen terlarut dalam air. Hasil penelitian didapat angka COD masing-masing $16 \mathrm{mg} / 1$ dan 91,5 mg/1 untuk angka COD air sungai di Delta Mahakam sebelum dan setelah melewati tempat pembuangan limbah cair industri migas sekitar Delta Mahakam. Nilai COD air sungai di Delta Mahakam hasil observasi sebelum melewati industri adalah $16 \mathrm{mg} / \mathrm{l}$ (Co), debit aliran sungai di Delta Mahakam 442,68 m3/dt (Qo), debit limbah cair buangan 0,0021 1/detik (Q1), dan nilai COD limbah cair 91,5 mg/1 (C1). Perhitungan nilai COD setelah melalui lokasi pembuangan limbah cair industri migas sekitar Delta Mahakam $103,44 \mathrm{mg} / 1$. Kenyataan dari analisis laboratorium nilai COD $24 \mathrm{mg} / 1$, hal ini 
disebabkan nilai COD merupakan jumlah atau banyaknya oksigen yang dipakai untuk mengoksidasikan zat karbon organik yang ada di perairan Sungai Mahakam, tidak hanya yang berasal dari limbah cair buangan industri migas sekitar Delta Mahakam yang relatip debitnya sangat kecil.

Derajat keasaman $(\mathrm{pH})$ merupakan parameter yang dapat menunjukkan kadar asam atau basa dalam suatu larutan melalui konsentrasi ion $\mathrm{H}+$. Hasil penelitian pada rata-rata $\mathrm{pH}$ air sungai di Delta Mahakam 7,9 masih di bawah ambang batas (6-9). Lewat aspek kimiawi, besarnya nilai $\mathrm{pH}$ akan berpengaruh terhadap suasana air, yang bisa mempengaruhi kehidupan biologi dan mikrobiologi.

Kenaikkan temperatur di dalam air sungai akan menyebabkan kecepatan reaksi, dekomposisi, dan aktivitas-aktivitas lain menjadi lebih tinggi, akibatnya konsumsi oksigen di dalam air menjadi lebih tinggi, sehingga pengaruh pertama akibat temperatur limbah cair buangan industri migas sekitar Delta Mahakam yang lebih tinggi adalah berkurangnya oksigen terlarut (Dissolve Oxygen) di dalam air yang berakibat dapat membahayakan kehidupan ikanikan di sungai. Akibat yang lain dengan kenaikkan temperatur yang lebih tinggi adalah akan terjadinya disosiasi ion amonium menjadi amonia, hal ini membahayakan bagi kehidupan ikan di sungai di samping itu juga mengakibatkan kehidupan mikroorganisme dan biota dalam air sungai akan terganggu. Oleh karena itu untuk temperatur buangan dari kegiatan migas sebaiknya jangan melebihi $40^{\circ} \mathrm{C}$ untuk perairan (sungai, danau, dan lain-lain) mengingat pertimbanganpertimbangan di atas. Temperatur yang diukur pada penelitian adalah rata-rata $28^{\circ} \mathrm{C}$.

Amoniak $\left(\mathrm{NH}_{3}\right)$ merupakan senyawa nitrogen yang menjadi $\mathrm{NH}$ pada $\mathrm{pH}$ rendah dan disebut amonium; amoniak sendiri berada dalam keadaan tereduksi. Amoniak dalam air permukaan berasal dari air seni dan tinja, juga dari oksidasi zat organis secara mikrobiologis yang berasal dari air alam atau air buangan industri dan penduduk. Kadar amoniak yang tinggi pada air sungai selalu menunjukkan adanya pencemaran. Dari penelitian air sungai di Delta Mahakam sebelum dan setelah melewati tempat pembuangan limbah cair industri migas sekitar Delta Mahakam, pada masing-masing 0,02 mg/1 dan 0,17 mg/1 (ambang batas 5 $\mathrm{mg} / 1$, SNI 06-2749-1999). Nilai AMONIA air sungai di Delta Mahakam sebelum melewati industri adalah $0,0219 \mathrm{mg} / \mathrm{l}(\mathrm{Co})$, debit aliran sungai di Delta Mahakam 442,68 m3/dt (Qo), debit limbah cair buangan 0,0021 l/ detik (Q1), nilai amonia limbah cair 0,1672 $\mathrm{mg} / \mathrm{l}$ (C1). Perhitungan nilai amoniak air sungai di Delta Mahakam setelah melewati lokasi pembuangan limbah cair 0,1008 mg/1. Dari hasil analisis laboratorium ternyata nilai amoniak 0,02 mg/1 sehingga pengaruh limbah cair industri migas sekitar Delta Mahakam kecil sekali dalam menaikkan tingkat pencemaran amoniak Sungai Mahakam. Demikian juga pada pengaruh peningkatan pencemaran amoniak akibat limbah cair industri migas sekitar Delta Mahakam sangat kecil. Pada kandungan amonia tinggi karena limbah penduduk yang banyak dan debit aliran sungai di Delta Mahakam yang kecil mengakibatkan kandungan amonia dalam air sungai di Delta Mahakam melebihi ambang batas yang ditentukan.

Sulfida, dalam air biasanya berasal dari terjadinya pembusukan bahan - bahan organik atau terjadi dari reduksi sulfat dalam kawah gunung api. Adanya sulfida dalam air sungai akan dapat merubah kesetimbangan kimia, timbulnya bau, dan adanya pertumbuhan mikroorganisme tertentu. Kadar sulfida yang tinggi akan menyebabkan pencemaran (ambang batas 0,002 mg/1, SNI 19-1664-1997. Setelah pembuangan limbah cair industri minyak Delta Mahakam, pada konsentrasi sulfida tidak terdeteksi, kemungkinan disebabkan debit sungai yang kecil, sulfida mudah mengendap, dan proses pembusukan oleh air sangat lambat. 
Konsentrasi phenol masing-masing 0,013 $\mathrm{mg} / 1$ dan 0,094 mg/1 untukair sungai di Delta Mahakam sebelum dan sesudah pembuangan limbah cair industri migas sekitar Delta Mahakam. Konsentrasi phenol yang tinggi (ambang batas 0,001 mg/1 SNI 06-2469-1999) setelah melewati pembuangan limbah cair industri migas sekitar Delta Mahakam ini memang dari hulu delta sudah tinggi. Nilai phenol air sungai di Delta Mahakam sebelum melewati industri adalah $0,0074 \mathrm{mg} / 1$ (Co), debit aliran sungai di Delta Mahakam 442,68 m3/dt (Qo), debit limbah cair buangan 0,0021 1/detik (Q1), dan nilai phenol limbah cair 0,094 mg/1 (C1). Perhitungan nilai phenol air sungai di Delta Mahakam setelah melewati lokasi pembuangan limbah cair naik sebesar $0,1544 \mathrm{mg} / 1$. Kenaikkan yang sangat kecil, sehingga dari hasil analisis laboratorium nilai phenol tidak terdeteksi.

Pada tabel 3, 4, 5, 6, dan 7 menjelaskan tentang peran mangrove dalam menyeimbangkan kualitas lingkungan perairan dan menetralisir kadar logam berat di perairan. Melalui akarnya yang ultra filter vegetasi ini dapat menyerap logamlogam berat. Pada tabel 3 dan gambar 1 memperlihatkan bahwa kandungan timbal $(\mathrm{Pb})$ yang didapatkan dari sampel air, tanah, dan udang memperlihatkan kandungan timbal $(\mathrm{Pb})$ yang rendah pada kelompok banyak mangrove dibandingkan mangrove sedang, sedikit, dan tidak ada mangrove.

Logam berat timbal $(\mathrm{Pb})$ merupakan salah satu bahan pencemar yang berbahaya bagi udang windu. Perubahan ekosistem akibat pencemaran akan mempengaruhi kehidupan udang windu yang hidup di dalamnya karena terjadi penyerapan dan cenderung membentuk senyawa kompleks dengan zat-zat yang ada di dalam tubuh udang, sehingga apabila terjadi akumulasi dapat mempengaruhi organ tubuhnya. Hal ini akan menyebabkan terganggunya metabolisme tubuh sehingga pertumbuhan udang akan terhambat yang akhirnya dapat menurunkan produksi. Di dalam perairan ambang batas logam berat timbal $(\mathrm{Pb})$ sebesar $0,05 \mathrm{mg} / 1$.

Badan perairan yang telah kemasukan senyawa atau ion-ion $\mathrm{Pb}$, sehingga jumlah $\mathrm{Pb}$ yang ada dalam badan perairan melebihi konsentrasi yang semestinya dan dapat mengakibatkan kematian bagi biota perairan tersebut. Berdasarkan penelitian yang pernah dilakukan pada tahun 1974 diketahui bahwa biota-biota perairan seperti crustacea akan mengalami kematian setelah 245 jam, bila pada badan perairan di mana biota itu berada terlarut $\mathrm{Pb}$ pada konsentrasi 2,75- $49 \mathrm{mg} / 1$. Dengan banyaknya mangrove pada tambak udang akan mengurangi kandungan timbal $(\mathrm{Pb})$, yang akan berdampak positif pada perkembangan tambak udang.

Logam berat lainnya adalah Cadmium (Cd). Hasil penelitian pada tabel 4 dan gambar 2 memperlihatkan bahwa kandungan Cadmium (Cd) yang didapatkan dari sampel air, tanah, udang, dan mangrove memperlihatkan kandungan timbal $(\mathrm{Pb})$ yang rendah pada kelompok banyak mangrove dibandingkan mangrove sedang, sedikit, dan tidak ada mangrove. Cadmium (Cd) merupakan salah satu jenis logam berat yang berbahaya karena elemen ini beresiko tinggi terhadap pembuluh darah. Kadmium berpengaruh terhadap manusia dalam jangka waktu panjang dan dapat terakumulasi pada tubuh khususnya hati dan ginjal. Secara prinsipil pada konsentrasi rendah berefek terhadap gangguan pada paru-paru, emphysema dan renal turbular disease yang kronis.

Logam cadmium menjadi popular setelah timbulnya pencemaran air sungai di kawasan Komamoto Jepang yang menyebabkan keracunan pada manusia. Logam ini biasanya selalu ada bercampur dengan logam lain, terutama dalam pertambangan seng (zn) dan timah hitam yang selalu ditemukan cadmium dengan kadar 0,2 - 0,4\%. Badan perairan yang terlarut dengan $\mathrm{Cd}$ dalam konsentrasi tertentu dapat membunuh biota perairan. Biota-boita yang tergolong bangsa 
udang-udangan (Crustacea) akan mengalami kematian dalam selang waktu 24-504 jam bila dalam badan perairan dimana biota ini hidup terlarut logam atau persenyawaan $\mathrm{Cd}$ pada rentang konsentrasi 0,005 -0,15 ppm. Hasil penelitian ini memberikan manfaat bahwa dengan banyaknya mangrove pada tambak udang akan mengurangi kandungan cadmium (Cd), yang akan berdampak positif pada perkembangan tambak udang.

Pada tabel 5 dan gambar 3 memperlihatkan bahwa kandungan minyak dan lemak yang didapatkan dari sampel air, tanah, udang, dan mangrove memperlihatkan kandungan minyak dan lemak yang rendah pada kelompok banyak mangrove dibandingkan mangrove sedang, sedikit dan tidak ada mangrove. Minyak dan lemak ( $\mathrm{M}$ \& L), merupakan zat pencemar yang sering dimasukkan ke dalam kelompok padatan, yaitu padatan yang mengapung di atas permukaan air. Nilai minyak lemak air sungai di Delta Mahakam sebelum dan setelah melewati tempat pembuangan limbah cair masing-masing masih di bawah ambang batas. Limbah buangan industri migas sekitar Delta Mahakam dengan debit 0,0021 1/detik dengan kadar minyak lemak 24,6 mg/1 dan debit aliran sungai di Delta Mahakam $442,68 \mathrm{~m}^{3} /$ detik. Kadar minyak lemak air sungai di Delta Mahakam setelah melewati lokasi buangan limbah cair industri migas sekitar Delta Mahakam sebesar 5,213 mg/1. Kenaikan kadar minyak lemak hanya sangat kecil dan relatif hampir sama. Ini dibuktikan dari hasil analisis laboratorium sebesar 5,213 $\mathrm{mg} / 1$. Bahan lemak tergabung benda organik yang sangat sukar terurai oleh bakteri. Terbentuknya emulsi air dalam minyak akan membentuk lapisan film di permukaan yang mengakibatkan penetrasi sinar matahari berkurang, pengambilan oksigen dari udara terhambat, terjadi penurunan oksigen terlarut dalam air.

Kadar logam merkuri (Hg) pada sampel air, tanah, udang, dan mangrove terdapat persamaan pada kelompok banyak mangrove, sedang mangrove, sedikit mangrove, dan tidak ada mangrove. Rata-rata merkuri $(\mathrm{Hg})$ adalah 0,0005 mg/ kg. Logam merkuri dihasilkan dari bijih sinabar, HgS yang mengandung unsur merkuri antara 0,1 \% - 4\%. Merkuri dan senyawa-senyawanya, seperti halnya dengan logam-logam yang lain tersebar di alam. Mulai dari batuan, air, udara dan bahkan dalam tubuh organism hidup. Penyebaran dari logam merkuri ini turut dipengaruhi oleh faktor geologi, fisika, kimia, dan biologi.

Keberadaan merkuri di alam, dan masuk ke dalam suatu tatanan lingkungan tertentu secara alamiah tidaklah menimbulkan efekefek merugikan bagi lingkungan karena masih dapat ditoleir oleh alam itu sendiri. Merkuri menjadi bahan pencemar sejak manusia mengenal industri, kemudian menggali sumberdaya alam, dan memanfaatkannya semaksimal mungkin untuk kebutuhannya. Pada tahun 1960 untuk pertama kalinya dunia dihebohkan oleh suatu jenis penyakit kerapuhan pada tulang, sehingga penderita tidak bisa sama sekali bergerak. Setiap bentuk gerakan yang dilakukan oleh penderita akan menyebabkan tulang si penderita patah. Melalui pengujian yang dilakukan, diketahui bahwa penyebab dari penyakit tersebut berawal dari keracunan logam berat merkuri yang masuk melalui ikan-ikan yang ditangkap di perairan Teluk Minamata untuk konsums.

Kadar Arsen (As) pada sampel air, tanah, udang, dan mangrove terdapat persamaan pada kelompok banyak mangrove, sedang mangrove, sedikit mangrove, dan tidak ada mangrove. Rata-rata Arsen (As) adalah 0,001 $\mathrm{mg} / \mathrm{kg}$. Arsen hampir selalu ditemukan secara alamiah di daerah pertambangan walaupun jumlahnya sangat sedikit. Logam ini biasanya selalu berbentuk senyawa kimia baik dengan logam lain, oksida maupun sulfur. Karena sangat beracun, logam ini tidak begitu banyak kegunaannya seperti halnya logam-logam lainnya, juga karena sifatnya yang kurang menguntungkan. Pada permukaan bumi, arsenik berada pada urutan 
ke-20 sebagai element yang berbahaya, ke-14 di lautan, dan unsur ke-12 berbahaya bagi manusia.

Arsen biasanya mencemari lingkuugan dalam bentuk debu yang berterbangan di udara (pencemaran udara) dan keracunan arsen pada orang atau hewan disebabkan karena menghisap debu tersebut. Orang yang menjadi korbannya ialah pekerjapekerja pabrik yang memproduksi fungisida, insetisida, pestisida yang mengandung arsen.

\section{SIMPULAN}

Pencemaran lingkungan dan tingkat beban pencemaran di tambak udang Delta Mahakam dapat dilihat dari kualitas air sungai, kualitas limbah cair, dan kandungan logam berat di tambak udang Delta Mahakam sebagai berikut ini.

Pertama, kualitas air sungai di Delta Mahakam sebelum dan sesudah melewati tempat pembuangan limbah cair industri migas sekitar Delta Mahakam pada saat penelitian dilakukan, seluruh parameter fisik, dan kimia telah memenuhi syarat baku mutu air golongan C. Parameter minyak lemak sebelum melewati lokasi pembuangan limbah cair industri migas sekitar Delta Mahakam tidak terdeteksi dan setelah melewati API II 5,213 mg/1 (ambang batas $25 \mathrm{mg} / 1$ ), setelah melewati $100 \mathrm{~m}$ dari pembuangan $107 \mathrm{mg} / 1$ (ambang batas $1000 \mathrm{mg} / 1$ ) dan setelah melewati $150 \mathrm{~m}$ dari pembuangan $139 \mathrm{mg} / 1$ (ambang batas $1000 \mathrm{mg} / 1$ ) serta pada pemukiman penduduk $242 \mathrm{mg} / 1$ (ambang batas $1000 \mathrm{mg} / 1$ ). Parameter sulfida tidak terdeteksi baik sebelum dan sesudah melewati pembuangan limbah (ambang batas $0,02 \mathrm{mg} / 1$ ), phenol $0,013 \mathrm{mg} / 1$ sebelum melewati, dan $0,094 \mathrm{mg} / 1$ setelah melewati (ambang batas 0,001 mg/1) serta tidak melebihi ambang batas untuk peruntukan air golongan $\mathrm{C}$.

Kedua, kualitas limbah cair industri migas sekitar Delta Mahakam telah sesuai dengan baku mutu yang ditetapkan, Debit sebenarnya dari limbah cair industri migas sekitar Delta Mahakam rata-rata pertahun di bawah debit maksimumnya. Parameter minyak lemak sebelum melewati lokasi pembuangan limbah cair industri migas sekitar Delta Mahakam di bawah ambang batas dan setelah melewati API II 5,213 mg/1 (ambang batas $25 \mathrm{mg} / 1$ ), setelah melewati 100 $\mathrm{m}$ dari pembuangan $107 \mathrm{mg} / 1$ (ambang batas $1000 \mathrm{mg} / 1$ ) dan setelah melewati $150 \mathrm{~m}$ dari pembuangan $139 \mathrm{mg} / \mathrm{l}$ (ambang batas 1000 $\mathrm{mg} / 1$ ) serta pada pemukiman penduduk 242mg/1 (ambang batas $1000 \mathrm{mg} / 1$ ).

Ketiga, keberadaan mangrove pada tambak udang memberikan dampak yang positif untuk menyeimbangkan kualitas lingkungan perairan dan menetralisir kadar logam berat di perairan. Banyaknya mangrove pada tambak udang dapat mengikat logam berat yang berupa $\mathrm{Pb}, \mathrm{Cd}$, minyak, dan lemak.

\section{DAFTAR PUSTAKA}

Sumaryono, 2007, Pemetaan Detail Areal Tambak di Lingkungan Delta Mahakam Menggunakan Citra Satelit Dan Sistem Informasi Geografi, Konsultan CV, Mitra Kaltim Persada.

Bengen, D.G. dkk, 2006, Delta Mahakam Dalam Ruang Dan Waktu. Ekosistem, Sumberdaya dan Pengelolaannya.

Dutrieux, 2001, dalam Bengen, D.G. Urgensi Pengelolaan Terpadu Bagi Berkelanjutan Ekosistem Delta Mahakam, Mitra Pesisir.

Hidayati D dkk, 2005, Manajemen Konflik Stakeholders Delta Mahakam, Piramida Publishing Bekerjasaama Dengan Pusaat penelitian Kependududkan Lembaga Ilmu Pengetahuan Indonesia.

Hamid, N., Evy, M. N, 1994, Pengamatan Dinamika Kualitas Lingkungan di Tambak Intensif dan Semi intensif, Laporan Tahunan BPAP, Jepara, 215228. 
Effendi, H, 2011, Telaah Kualitas Air; Bagi Pengelolaan Sumber Daya Dan Lingkungan Perairan, Yogyakarta: Kanisius.

Anonim, 2004, Keputusan Menteri Negara Lingkungan Hidup Nomor: 51 tahun 2004 Tentang Baku Mutu Air Laut, Jakarta: Kantor Kementerian Lingkungan Hidup RI.

Palar, H, 2008, Pencemaran dan Toksikologi Logam Berat, Jakarta: Rineka Cipta.

Darmiyati, M., dan Kusmana, C., 1995, Akumulasi Logam Berat (Mn, Zn, Cu) pada hizophora mucronata di Hutan Tanaman Mangrove Cilacap, Jakarta: Majalah Duta Rimba Edisi MaretApril/177-178/XXI/1995.

Darmono, 2001, Lingkungan Hidup dan Pencemaran. Jakarta: Universitas Indonesia Press.

Sugiharto, B, dan Sukirman, 2004, Hidrokarbon Dan Minyak Bumi, Bagian Proyek Pengembangan Kurikulum Direktorat Pendidikan Menengah Kejuruan Direktorat Jenderal Pendidikan Dasar Dan Menengah Departemen Pendidikan Nasional. 